\title{
UV Activation of Persulfate for Removal of Penicillin G Antibiotics in Aqueous Solution
}

\author{
Samira Norzaee, ${ }^{1}$ Edris Bazrafshan, ${ }^{2}$ Babak Djahed, ${ }^{1}$ \\ Ferdos Kord Mostafapour, ${ }^{3}$ and Razieh Khaksefidi ${ }^{4}$ \\ ${ }^{1}$ Department of Environmental Health Engineering, Iranshahr University of Medical Sciences, Iranshahr, Iran \\ ${ }^{2}$ Torbat Heydariyeh University of Medical Sciences, Torbat Heydariyeh, Iran \\ ${ }^{3}$ Health Promotion Research Center, Faculty of Health, Zahedan University of Medical Sciences, Zahedan, Iran \\ ${ }^{4}$ Department of Environmental Health Engineering, Faculty of Health, Zahedan University of Medical Sciences, Zahedan, Iran
}

Correspondence should be addressed to Babak Djahed; babak.djahed@gmail.com

Received 7 April 2017; Revised 14 June 2017; Accepted 10 July 2017; Published 8 August 2017

Academic Editor: Sandra Babic

Copyright (c) 2017 Samira Norzaee et al. This is an open access article distributed under the Creative Commons Attribution License, which permits unrestricted use, distribution, and reproduction in any medium, provided the original work is properly cited.

\begin{abstract}
Penicillin G (PG) is one of the most widely consumed antibiotics around the world. Release of PG in environment may lead to contamination of water resources. The aim of the present work is to assess feasibility of applying UV-activated persulfate process in removal of $\mathrm{PG}$ from aquatic environments. The study examined the effect of $\mathrm{pH}(3-11)$, persulfate initial concentration $(0.5-3 \mathrm{mM})$, reaction time (15-90 minutes), and initial concentration of PG (0.02-0.14 mM) on PG decomposition. Also, the pseudo-first-order kinetic model was used for kinetic analysis of PG removal. The results indicated that UV-activated persulfate process can effectively eliminate PG from water. The highest PG removal efficiency was obtained as $94.28 \%$ at $\mathrm{pH} 5$, and the decomposition percentage was raised by increasing persulfate dose from 0.5 to $3 \mathrm{mM}$ and the reaction time from 15 to 90 minutes. Besides, the removal efficiency decreased through increasing the initial concentration of PG. UV-activated persulfate process effectively decomposes PG and eliminates it from water.
\end{abstract}

\section{Introduction}

Pharmaceutical compounds may not differ from other chemicals such as pesticides and herbicides in terms of environmental hazards. These compounds enter the aquatic environment through wastewater of the pharmaceutical industry as well as the final consumer in a metabolized or nonmetabolized form [1]. Among the pharmaceutical compounds, antibiotics have an important contribution to the environmental pollution due to high consumption in medicine and veterinary [2]. Considering 30-90 percent of nonmetabolized antibiotics in human and animal body released into the environment through urine and feces in the form of active ingredients, microbial resistance would be expected in our environment [3].

Penicillin G (PG) is one of commonly used antibiotics (Figure 1) that is utilized for the treatment of various human bacterial infections $[4,5]$. A part of PG may pass through aerobic and anaerobic treatment units of wastewater treatment plants and some studies indicated that the concentrations of PG in raw and treated wastewater were 153 and $1.68 \mathrm{mg} \mathrm{L}^{-1}$, respectively [6]. Hence, considering the health risk related to the entering of the antibiotics to the environment, they require approaching an allowable discharge limit before being disposed into the environment and aquatic ecosystems.

Recent studies applied various methods for removing pharmaceutical compounds such as reverse osmosis [7], adsorption on activated carbon [8], and ozonation [9] as well as advanced oxidation systems (AOP) such as Fenton or Photo-Fenton [10], ultrasound [11], preoxidation using UV lamps [12], and photocatalysis with $\mathrm{TiO}_{2}$ [13]. Due to some troubles in using the aforementioned processes, advanced oxidation system has gained interest in recent years [14].

AOP technology mainly works based on producing reactive species resulting from decomposition of oxidants such as persulfate $\left(\mathrm{S}_{2} \mathrm{O}_{8}{ }^{-2}\right)$; this compound through producing $\mathrm{SO}_{4}^{-\bullet}$ radical (a very powerful oxidant with 


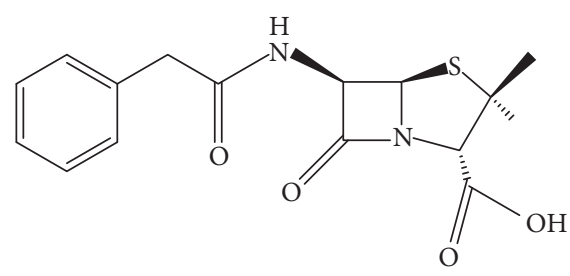

FIgURE 1: Structural formula of Penicillin G.

oxidation-reduction potentials of 2.5-3.1 V) could effectively decompose organic materials [15]. Sulfate radical is a unique oxidant because of its characteristics, including its high stability compared to hydroxyl radicals, high reaction rate, and effective influences on organic matters [16, 17]. Overall, $\mathrm{SO}_{4}{ }^{-\bullet}$ directly changes the electron produced from organic compounds into organic radical cations [18]. The efficiency of PS alone has been less to decompose organic compounds; in addition, it needs to be activated in order to accelerate the process of sulfate radical production. PS is usually activated by heat, UV, and transition metals [17]. UV activation, among these methods, not only is an effective way of water disinfection, but also can be considered as a form of energy for persulfate activation [19]. Several studies utilized this method to eliminate compounds such as acid blue 113 [20], tetramethylammonium hydroxide [19], and sulfamethazine [21]. PS activation by UV radiation produces two moles of sulfate radical from a mole of sulfate according to

$$
\mathrm{S}_{2} \mathrm{O}_{8}{ }^{2-} \stackrel{\mathrm{UV}}{\longrightarrow} 2 \mathrm{SO}_{4}{ }^{\circ}
$$

The aim of this study is to examine the feasibility of UV/PS process in PG decomposition from aquatic solutions. Also, the effects of $\mathrm{pH}$, initial concentration of PS, reaction time, and initial concentration of PG on PG decomposition efficiency were investigated through UV/PS process.

\section{Materials and Methods}

2.1. Apparatus and Materials. Sodium persulfate $\left(\mathrm{Na}_{2} \mathrm{~S}_{2} \mathrm{O}_{8}\right)$ and Penicillin $\mathrm{G}$ sodium were purchased from Sigma-Aldrich Chemical Company. Mercury (II) sulfate, potassium dichromate, silver sulfate, sulfuric acid, and sodium hydroxide were prepared from Merck Company. A $30 \mathrm{~W}$ ultraviolet lamp (Philips, with maximum emission at $254 \mathrm{~nm}$ ) with $9 \mathrm{~cm}$ length and diameter of $28 \mathrm{~mm}$ was used in the experiments. Concentration of PG and COD was determined through a UV-Vis spectrophotometer (HACH, DR 5000).

2.2. Methodology. The study was conducted through batch mood experiment. A Plexiglas square shape reactor (total volume of 2 liters) was utilized in the experiments (Figure 2); and it was equipped with a UVC lamp that was installed $7 \mathrm{~cm}$ above the sample surface, the intensity of UV irradiation was $950 \mu \mathrm{w} / \mathrm{m}^{2}$.

PG and PS stock solutions were prepared daily using deionized water. To make solutions with different concentrations, the stock solution was diluted using deionized water.

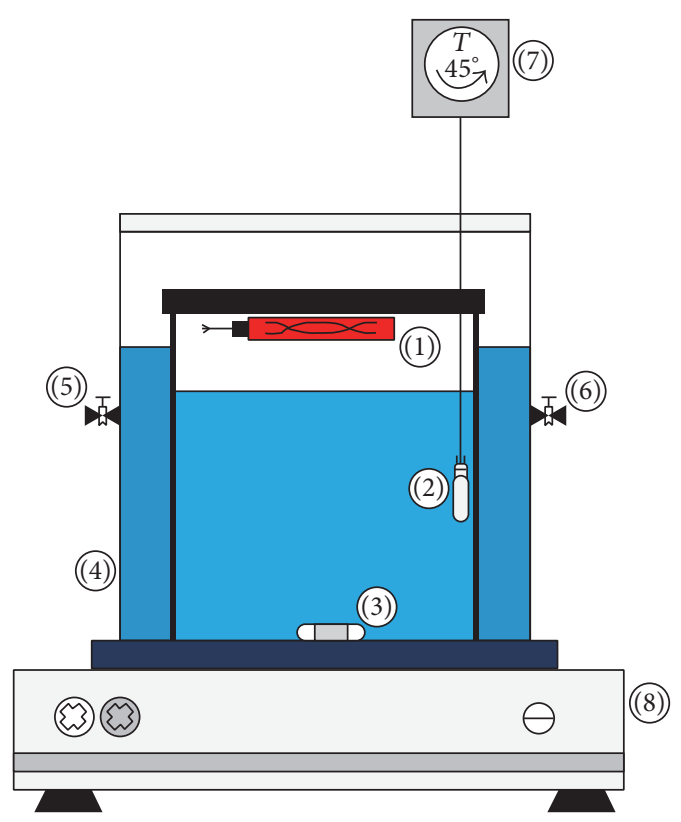
(1) UV lamp
(2) Thermometer probe
(3) Magnet
(4) Cooling water container
(5) Water inlet
(6) Water outlet
(7) Thermometer
(8) Stirrer

FIgURE 2: Setup for experiments.

Also, the reactor was covered with aluminum sheets for the possibility of UV light reflection output. Besides, temperature of the solution was adjusted to $25 \pm 3^{\circ} \mathrm{C}$ through adjusting the cooling water flow and it was monitored by a thermometer continuously. The effect of several parameters including $\mathrm{pH}$ $(3,5,7,9$, and 11$)$, contact time (15, 30, 60, and 90 minutes), initial concentration of PS $(0.5,1,1.5,2,2.5$, and $3 \mathrm{mM})$, and different concentrations of PG $(0.02-0.14 \mathrm{mM})$ on PG decomposition was also investigated. For this purpose, a parameter was changed and three parameters were kept constant in each examination period. $\mathrm{pH}$ of the solution was adjusted using $\mathrm{HCl}$ and $\mathrm{NaOH}$; and then, it was transferred to the reactor after adding PS. To keep the solution homogeneous during reaction time, the magnetic stirrer with speed of $100 \mathrm{rpm}$ was used. Next, in order to activate PS, it was radiated by UV emission. Then, $10 \mathrm{ml}$ of the solution was taken from the upper part of the reactor as the sample at the defined time intervals. To determine the remaining PG in solution, the concentration of this substance at a wavelength of $290 \mathrm{~nm}$ was reported; also, in order to determine the concentration of the remaining PG along with the intermediate compounds resulting from decomposition of $\mathrm{PG}$, the amount of COD was measured in each experiment. Besides, for surveying the decomposition of PG by UV alone, the concentration of $0.02 \mathrm{mM}$ of PG was irradiated with UV at various contact times; moreover, to examine the effect of PS alone, in darkness condition, the degradation of PG $(0.02 \mathrm{mM})$ was studied in the presence of PS $(2 \mathrm{mM})$. 


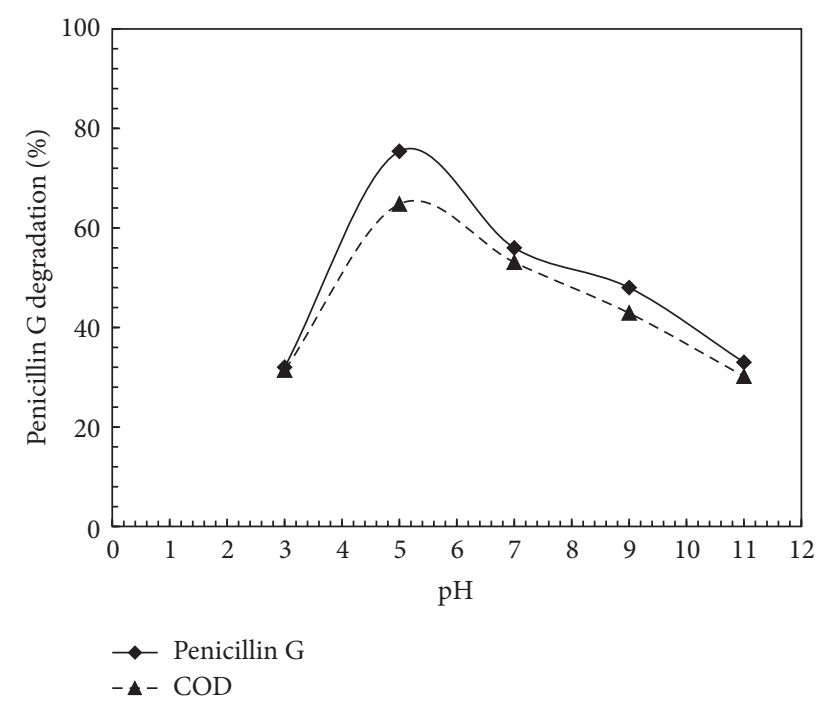

FIGURE 3: Effect of $\mathrm{pH}$ on PG and COD degradation by UV-activated persulfate. $\mathrm{PG}=0.02 \mathrm{mM}$, time $=60 \mathrm{~min}$, and persulfate $=2 \mathrm{mM}$.

2.3. Kinetics of the Reaction. Kinetics of PG decomposition by UV/PS were investigated through pseudo-first-order equation (see (2)). Most studies indicated that oxidation of the organic pollutants by PS follows the pseudo-first-order equation $[22,23]$.

$$
-\frac{d \mathrm{PG}}{d t}=k[\mathrm{PG}]
$$

Equation (2) can be rewritten as follows [24]:

$$
\ln \frac{C_{i}}{C_{t}}=k t
$$

where $C_{i}\left(\mathrm{mg} \mathrm{L}^{-1}\right)$ is $\mathrm{PG}$ concentration $\left(\mathrm{mg} \mathrm{L}^{-1}\right)$ at time $t, k$ is the reaction rate $\left(\mathrm{min}^{-1}\right)$, and $t(\mathrm{~min})$ represents the reaction time.

\section{Results and Discussion}

3.1. Effect of $p H$. The removing efficiency of $P G$ in various $p H$ values $(3,5,7,9$, and 11$)$ was investigated in order to evaluate the effect of $\mathrm{pH}$ on PG removal in UV/PS process. For this purpose, PS initial concentration (2 $\mathrm{mM})$, PG initial concentration $(0.02 \mathrm{mM})$, and reaction time (60 minutes) were kept constant. The results are shown in Figure 3. According to Figure 3, the highest PG removal rate $(75.4 \%)$ is related to $\mathrm{pH}$ 5. The results revealed that increasing of the $\mathrm{pH}$ from 3 to 5 intensifies PG removal efficiency, while increasing the $\mathrm{pH}$ from 5 to 11 may decrease the efficiency up to about $53.2 \%$. Also, as seen in Figure 3, COD removal at $\mathrm{pH}$ of 3, 5, 7, 9, and 11 was $31.4,64.8,53.1,42.9$, and 30.2 percent, respectively, where the highest removal rate was observed at $\mathrm{pH} 5$. As it is known, one of the most influential parameters of chemical processes, especially in advanced oxidation processes, is the $\mathrm{pH}$ of the solution, which the rate of chemical reactions relies on. According to the results of the conducted studies,
$\mathrm{pH}$ directly affects radical production [25]. According to the results of this study, the efficiency of $\mathrm{PG}$ removal reduces as $\mathrm{pH}$ increases. Hydroxyl radicals $\left(\mathrm{HO}^{\circ}\right)$ dominate at $\mathrm{pH} 11$ in accordance with (4). Based on these results, decrease in efficiency may be attributed to the reaction between hydroxyl radical and sulfate radical, which will lead to the consumption of both radicals (see (5)) [26].

$$
\begin{aligned}
& \mathrm{SO}_{4}^{-\bullet}+\mathrm{OH}^{-} \longrightarrow \mathrm{SO}_{4}{ }^{2-}+\mathrm{OH}^{\bullet} \quad \text { Alkaline } \mathrm{pH} \\
& \mathrm{SO}_{4}{ }^{-\bullet}+\mathrm{OH}^{\bullet} \longrightarrow \mathrm{HSO}_{4}{ }^{-}+0.5 \mathrm{O}_{2} \\
& \mathrm{OH}^{\bullet}+\mathrm{OH}^{-} \longrightarrow \mathrm{O}^{\bullet-}+\mathrm{H}_{2} \mathrm{O}
\end{aligned}
$$

Moreover, the concentration of hydroxyl ions at high $\mathrm{pH}$ increases scavenging the hydroxyl radical (see (6)) [16]. In other words, at higher $\mathrm{pH}$ values, the presence of high amounts of $\mathrm{OH}^{*}$ radicals causes radical-radical reactions and then leads to the consequent deactivation of $\mathrm{OH}^{\bullet}$ radicals [27]. In addition, at low $\mathrm{pH}, \mathrm{SO}_{4}{ }^{-\bullet}$ is dominant. However, in a highly acidic condition, $\mathrm{SO}_{4}{ }^{-\bullet}$ is scavenged by the $\mathrm{SO}_{4}{ }^{-\bullet}$ itself and it decreases the removal efficiency [28]:

$$
\mathrm{SO}_{4}^{-\cdot}+\mathrm{SO}_{4}^{-\cdot} \longrightarrow \mathrm{S}_{2} \mathrm{O}_{8}{ }^{2-}
$$

At a $\mathrm{pH}$ close to neutral, $\mathrm{SO}_{4}{ }^{-\bullet}$ and $\mathrm{OH}^{\bullet}$ are dominant and they decompose PG according to the following [29]:

$$
\begin{aligned}
& 2 \mathrm{SO}_{4}{ }^{-\bullet}+\mathrm{PG} \longrightarrow \mathrm{PG}^{\bullet}+\text { products } \\
& \mathrm{SO}_{4}{ }^{-\bullet}+\mathrm{PG}^{\bullet} \longrightarrow \text { chain termination }
\end{aligned}
$$

Therefore, at a $\mathrm{pH}$ close to neutral, the sulfate radical demonstrated the best efficiency of decomposing pollutants.

3.2. Effect of Persulfate Concentration. One of the effective parameters of advanced oxidization processes is the concentration of the oxidizer. Among the different oxidizers, sulfate radical is capable of decomposing resistant organic compounds. It directly and indirectly decomposes organic compounds. In direct method, sulfate radical decomposes the pollutant directly (see (9)); and in indirect method, it highly decomposes the pollutants through producing hydroxyl radicals [29]:

$$
\begin{aligned}
& \mathrm{SO}_{4}{ }^{-\bullet}+\mathrm{H}_{2} \mathrm{O} \longrightarrow \mathrm{OH}^{\bullet}+\mathrm{SO}_{4}{ }^{2-}+\mathrm{H}^{+} \\
& \mathrm{OH}^{\bullet}+\mathrm{PEN} \mathrm{G} \longrightarrow \text { products }
\end{aligned}
$$

In order to survey the effect of initial concentration of PS on PG removal efficiency, various initial concentrations of PS $(0.5,1$, and 1.5 and $2,2.5$, and $3 \mathrm{mM})$ were examined. For this purpose, PG concentration $(0.02 \mathrm{mM})$ and reaction time (60 minutes) were constant and $\mathrm{pH}$ was adjusted to 5. According to Figure 4, the results revealed that, through increasing PS concentration from 0.5 to $3 \mathrm{mM}$, PG removal rate increases. Then, by a further increase in concentration of PS, the removal efficiency increases at a low slope. The highest efficiency was also obtained at $82.3 \%$ at a PS concentration of $3 \mathrm{mM}$. As seen in Figure 4, COD removal rate at concentrations of $0.5,1,1.5,2,2.5$, and $3 \mathrm{mM}$ of PS was obtained at 


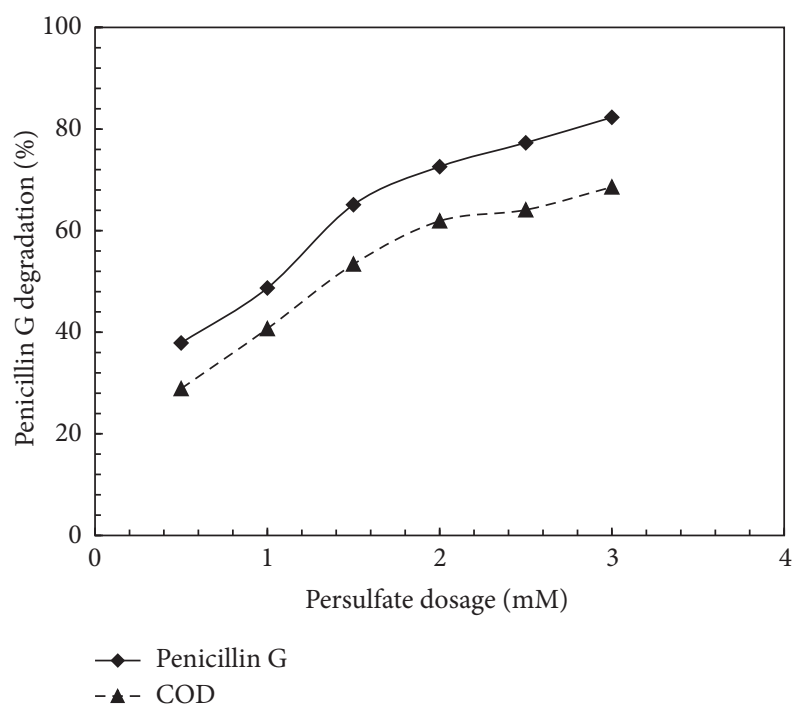

Figure 4: Effect of persulfate concentration on PG and COD degradation by UV-activated persulfate. $\mathrm{PG}=0.02 \mathrm{mM}$, time $=$ $60 \mathrm{~min}$, and $\mathrm{pH}=5$.

28.9, 40.7, 53.4, 61.9, 64.1, and 70.6 percent, respectively, where the highest removal rate was observed at a concentration of $3 \mathrm{mM}$ that it was similar to the removal pattern of PS concentration. The increasing of COD and PG removal efficiency through increasing of PS concentration is probably due to increased production of $\mathrm{SO}_{4}{ }^{-\bullet}$. However, results of some studies indicated that increasing of PS concentration more than a certain amount not only may not increase the decomposition of pollutants but also is a factor of abstraction and consumption of sulfate radical and, consequently, decreasing of the decomposition efficiency [26]:

$$
\mathrm{SO}_{4}{ }^{-\bullet}+\mathrm{S}_{2} \mathrm{O}_{8}{ }^{2-} \longrightarrow \mathrm{SO}_{2}{ }^{2-}+\mathrm{S}_{2} \mathrm{O}_{8}^{-\bullet}
$$

Also, high concentrations of PS under UV radiation can produce more $\mathrm{H}^{+}$and this results in a reduction of $\mathrm{pH}$ influencing removal efficiency [30]. However, in this study, the highest utilized persulfate dose $(3 \mathrm{mM})$ has not reached the critical level to reduce the rate of decomposing PG, and for this reason the PS inhibitory effect was not observed. Therefore, in current survey, it can be concluded that the concentration of $3 \mathrm{mM}$ was as the desired concentration of PS.

\subsection{Effect of Penicillin G Concentration and Reaction Time.} In order to investigate the effect of the initial concentration of PG as well as reaction time on UV/PS process, the PG removal efficiency in various initial concentrations of PG $(0.02-0.14 \mathrm{mM})$ and at 4 different reaction times (15-90 minutes) was investigated; it is worth mentioning that the PS concentration and $\mathrm{pH}$ were fixed at $3 \mathrm{mM}$ and 5 , respectively. According to the obtained results (Figure 5), by increasing of reaction time from 15 to 30 minutes, the removal rate increased at all understudied concentrations so that, at an initial concentration of $0.02 \mathrm{mM}$ of PG, the removal rate increased from 60.44 to 80.11 percent. However, by increasing the reaction time to 90 minutes, the removal efficiency curve

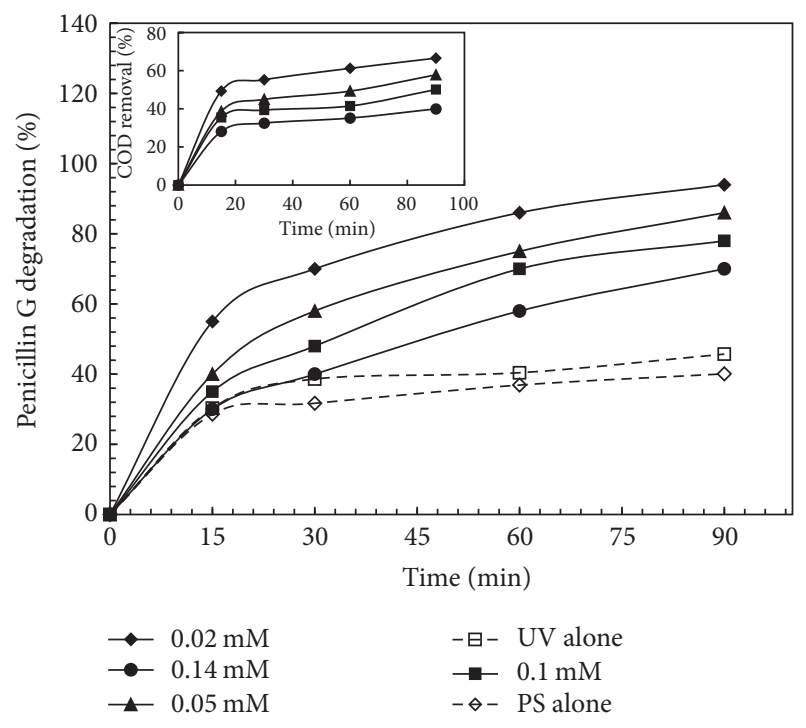

FIGURE 5: Effect of initial concentration of $P G$ and reaction time on PG and COD degradation by processes of UV-activated persulfate, PS alone, and UV alone. Persulfate $=3 \mathrm{mM}$ and $\mathrm{pH}=5$.

is augmented with a low slope. Kordkandi and Forouzesh [23] in a study concluded that, during time increasing, the lower slope of the PG removal curve is attributed to the decreasing of the PG concentration; this situation leads to lower probable contact of pollutant with radicals. As shown in Figure 5, PG removal rate declined by increasing of PG initial concentration; furthermore, the COD removal rates at $90 \mathrm{~min}$ for concentrations of $0.02,0.05,0.1$, and $0.14 \mathrm{mM}$ were obtained at $66.5,57.8,50.1$, and 39.9 percent, respectively. Since forming free produced radicals is constant for a defined concentration of PS, therefore, available sulfate radicals for decomposing of high concentrations of PG may be inadequate; this condition leads to decrease of PG removal by increasing of initial PG concentration. In addition, oxidation of PG intensifies concentration of intermediate compounds; these produced intermediate compounds consume the radicals; this would reduce PG decomposition through free radicals [31-33]. Also, regarding the short lifetime of the produced free radicals such as sulfate radical and hydroxyl radical, which are about 4 seconds and 20 nanoseconds, respectively, they may react with PG molecules immediately after production and before reaction with intermediate compounds. For this reason, lower concentrations of PG lead to less creation of intermediate compounds; hence, the removal rate is enhanced, whereas, with increasing PG concentrations where further intermediate compounds are formed, the removal efficiency is dropped [15]. Figure 5 also represents the results of comparing PG removal rates through the processes of UV/PS, PS alone, and UV alone. According to the obtained results, UV/PS process is generally a more effective method than the other two methods in removing of PG. As known, the main mechanism in UV alone is direct UV radiation that it degrades the pollutants directly, while, at PS alone, the dominant mechanism is oxidation using PS. Although PS is a strong oxidant with a redox potential of $2.01 \mathrm{~V}$, oxidation 


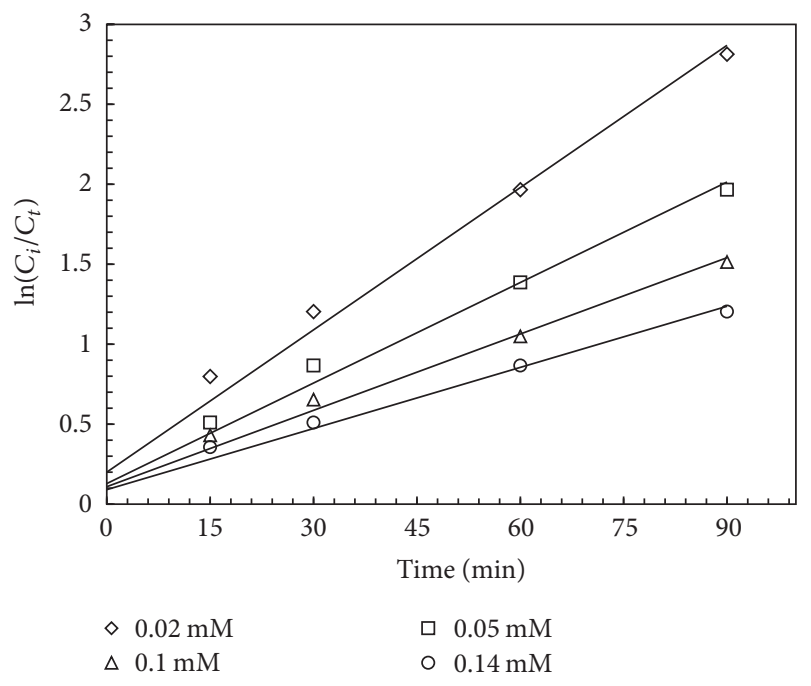

Figure $6: \ln \left(C_{i} / C_{t}\right)$ versus reaction time.

TABLE 1: Rate constant $(K)$ and correlation coefficient $\left(R^{2}\right)$ for different initial concentrations of PG.

\begin{tabular}{lcc}
\hline$C_{t}(\mathrm{mM})$ & $K\left(\mathrm{~min}^{-1}\right)$ & $R^{2}$ \\
\hline 0.02 & 0.0296 & 0.9903 \\
0.05 & 0.0259 & 0.9907 \\
0.1 & 0.0171 & 0.9802 \\
0.14 & 0.0127 & 0.985 \\
\hline
\end{tabular}

by the PS is often a slow process [19]. Similar results were reported where degradation of various contaminants was distinctly promoted in the UV/PS system compared with UV alone [30, 34]. These promotions were related to the generation of $\mathrm{SO}_{4}{ }^{-\bullet}$ through the combination of chemical oxidation and photodegradation, which has the effect of synergistic enhancement [34]. PS in the presence of UV can be converted into two $\mathrm{SO}_{4}{ }^{-\bullet}$ molecules (see (1)) [21]. Then, according to reactions of (7) and (8), it oxidizes PG.

Besides, in order to study the PG decomposition kinetics using UV/PS process, the pseudo-first-order model was utilized which is usually used to describe the decomposition of various organic compounds, especially antibiotics [30, 35]. In the pseudo-first-order kinetic model, slope of $\ln \left(C_{i} / C_{t}\right)$ against the reaction time is equal to $K$ constant (Figure 6). Also, the rate constant of the reaction $(K)$ and the regression coefficients of $R^{2}$ were indicated in Table 1 .

\section{Conclusion}

The current research showed that the PG decomposition efficiency through UV/PS process is influenced by parameters such as $\mathrm{pH}$, initial concentration of PS, initial concentration of PG, and reaction time. According to the obtained results, applying UV is an effective method for activation of PS in order to remove PG. Besides, we found that the highest removal efficiency of 94.28 percent was obtained at $\mathrm{pH} 5$, a PS concentration of $3 \mathrm{mM}$, reaction time of 90 minutes, and PG concentration of $0.02 \mathrm{mM}$. Also, it was revealed that, by increasing initial concentration of PG from 0.02 to $0.14 \mathrm{mM}$, the constant reaction rate $(k)$ reduced from 0.0296 to $0.0127 \mathrm{~min}^{-1}$. Besides, the results of COD removal demonstrated that the UV/PS process may be effectively used for $P G$ decomposition. Finally, it was found that UV/PS process can be considered as an effective method for removing PG from pharmaceutical industry as well as hospital wastewater.

\section{Conflicts of Interest}

The authors declare that they have no conflicts of interest.

\section{Acknowledgments}

The authors would like to thank environmental chemistry laboratory of Zahedan University of Medical Sciences for financial support of this research project.

\section{References}

[1] Z. Aksu and Ö. Tunç, "Application of biosorption for penicillin G removal: Comparison with activated carbon," Process Biochemistry, vol. 40, no. 2, pp. 831-847, 2005.

[2] M. V. Walter and J. W. Vennes, "Occurrence of multipleantibiotic-resistant enteric bacteria in domestic sewage and oxidation lagoons," Applied and Environmental Microbiology, vol. 50, no. 4, pp. 930-933, 1985

[3] H. Liu, W. Liu, J. Zhang, C. Zhang, L. Ren, and Y. Li, "Removal of cephalexin from aqueous solutions by original and $\mathrm{Cu}(\mathrm{II}) / \mathrm{Fe}$ (III) impregnated activated carbons developed from lotus stalks Kinetics and equilibrium studies," Journal of Hazardous Materials, vol. 185, no. 2-3, pp. 1528-1535, 2011.

[4] K. D. Brown, J. Kulis, B. Thomson, T. H. Chapman, and D. B. Mawhinney, "Occurrence of antibiotics in hospital, residential, and dairy effluent, municipal wastewater, and the Rio Grande in New Mexico," Science of the Total Environment, vol. 366, no. 2-3, pp. 772-783, 2006.

[5] J. W. Peterson, L. J. Petrasky, M. D. Seymour, R. S. Burkhart, and A. B. Schuiling, "Adsorption and breakdown of penicillin antibiotic in the presence of titanium oxide nanoparticles in water," Chemosphere, vol. 87, no. 8, pp. 911-917, 2012.

[6] N. Le-Minh, S. J. Khan, J. E. Drewes, and R. M. Stuetz, "Fate of antibiotics during municipal water recycling treatment processes," Water Research, vol. 44, no. 15, pp. 4295-4323, 2010.

[7] J. Radjenović, M. Petrović, F. Ventura, and D. Barceló, "Rejection of pharmaceuticals in nanofiltration and reverse osmosis membrane drinking water treatment," Water Research, vol. 42, no. 14, pp. 3601-3610, 2008.

[8] J. Rivera-Utrilla, G. Prados-Joya, M. Sánchez-Polo, M. A. FerroGarcía, and I. Bautista-Toledo, "Removal of nitroimidazole antibiotics from aqueous solution by adsorption/bioadsorption on activated carbon," Journal of Hazardous Materials, vol. 170, no. 1, pp. 298-305, 2009.

[9] S. Esplugas, D. M. Bila, L. G. T. Krause, and M. Dezotti, "Ozonation and advanced oxidation technologies to remove endocrine disrupting chemicals (EDCs) and pharmaceuticals and personal care products (PPCPs) in water effluents," Journal of Hazardous Materials, vol. 149, no. 3, pp. 631-642, 2007. 
[10] C. Sirtori, A. Zapata, I. Oller, W. Gernjak, A. Agüera, and S. Malato, "Decontamination industrial pharmaceutical wastewater by combining solar photo-Fenton and biological treatment," Water Research, vol. 43, no. 3, pp. 661-668, 2009.

[11] F. Méndez-Arriaga, R. A. Torres-Palma, C. Pétrier, S. Esplugas, J. Gimenez, and C. Pulgarin, "Ultrasonic treatment of water contaminated with ibuprofen," Water Research, vol. 42, no. 16, pp. 4243-4248, 2008.

[12] F. Yuan, C. Hu, X. Hu, J. Qu, and M. Yang, "Degradation of selected pharmaceuticals in aqueous solution with UV and $\mathrm{UV} / \mathrm{H}_{2} \mathrm{O}_{2}$," Water Research, vol. 43, no. 6, pp. 1766-1774, 2009.

[13] M. Farzadkia, E. Bazrafshan, A. Esrafili, J.-K. Yang, and M. Shirzad-Siboni, "Photocatalytic degradation of Metronidazole with illuminated $\mathrm{TiO}_{2}$ nanoparticles," Journal of Environmental Health Science and Engineering, vol. 13, no. 1, 2015.

[14] P. L. Mohamadi, E. Bazrafshan, M. Noroozifar, and A. AnsariMoghaddam, "Ethyl benzene removal from aqueous environments by catalytic ozonation process using MgO nanoparticles," Journal of Mazandaran University of Medical Sciences, vol. 26, no. 143, pp. 129-144, 2016.

[15] S. Yang, X. Yang, X. Shao, R. Niu, and L. Wang, "Activated carbon catalyzed persulfate oxidation of Azo dye acid orange 7 at ambient temperature," Journal of Hazardous Materials, vol. 186, no. 1, pp. 659-666, 2011.

[16] R. H. Waldemer, P. G. Tratnyek, R. L. Johnson, and J. T. Nurmi, "Oxidation of chlorinated ethenes by heat-activated persulfate: Kinetics and products," Environmental Science and Technology, vol. 41, no. 3, pp. 1010-1015, 2007.

[17] S. Yang, P. Wang, X. Yang et al., "Degradation efficiencies of azo dye Acid Orange 7 by the interaction of heat, UV and anions with common oxidants: Persulfate, peroxymonosulfate and hydrogen peroxide," Journal of Hazardous Materials, vol. 179, no. 1-3, pp. 552-558, 2010.

[18] C. Tan, N. Gao, Y. Deng, W. Rong, S. Zhou, and N. Lu, "Degradation of antipyrine by heat activated persulfate," Separation and Purification Technology, vol. 109, pp. 122-128, 2013.

[19] C.-W. Wang and C. Liang, "Oxidative degradation of TMAH solution with UV persulfate activation," Chemical Engineering Journal, vol. 254, pp. 472-478, 2014.

[20] H.-Y. Shu, M.-C. Chang, and S.-W. Huang, "UV irradiation catalyzed persulfate advanced oxidation process for decolorization of Acid Blue 113 wastewater," Desalination and Water Treatment, vol. 54, no. 4-5, pp. 1013-1021, 2015.

[21] Y.-Q. Gao, N.-Y. Gao, Y. Deng, Y.-Q. Yang, and Y. Ma, "Ultraviolet (UV) light-activated persulfate oxidation of sulfamethazine in water," Chemical Engineering Journal, vol. 195-196, pp. 248253, 2012.

[22] F. Gong, L. Wang, D. Li et al., "An effective heterogeneous iron-based catalyst to activate peroxymonosulfate for organic contaminants removal," Chemical Engineering Journal, vol. 267, pp. 102-110, 2015.

[23] S. A. Kordkandi and M. Forouzesh, "Application of full factorial design for methylene blue dye removal using heat-activated persulfate oxidation," Journal of the Taiwan Institute of Chemical Engineers, vol. 45, no. 5, pp. 2597-2604, 2014.

[24] F. J. Real, J. L. Acero, J. F. Benitez, G. Roldan, and F. Casas, "Oxidation of the emerging contaminants amitriptyline hydrochloride, methyl salicylate and 2-phenoxyethanol by persulfate activated by UV irradiation," Journal of Chemical Technology and Biotechnology, vol. 91, no. 4, pp. 1004-1011, 2016.

[25] S. Rahim Pouran, A. A. Abdul Raman, and W. M. A. Wan Daud, "Review on the application of modified iron oxides as heterogeneous catalysts in Fenton reactions," Journal of Cleaner Production, vol. 64, pp. 24-35, 2014.

[26] Y. Liu, X. He, Y. Fu, and D. D. Dionysiou, "Kinetics and mechanism investigation on the destruction of oxytetracycline by UV-254 nm activation of persulfate," Journal of Hazardous Materials, vol. 305, pp. 229-239, 2016.

[27] S. Norzaee, B. Djahed, R. Khaksefidi, and F. K. Mostafapour, "Photocatalytic degradation of aniline in water using $\mathrm{CuO}$ nanoparticles," Journal of Water Supply: Research and Technology-AQUA, vol. 66, no. 3, pp. 178-185, 2017.

[28] S. G. Huling, S. Ko, S. Park, and E. Kan, "Persulfate oxidation of MTBE- and chloroform-spent granular activated carbon," Journal of Hazardous Materials, vol. 192, no. 3, pp. 1484-1490, 2011.

[29] K.-C. Huang, R. A. Couttenye, and G. E. Hoag, "Kinetics of heat-assisted persulfate oxidation of methyl tert-butyl ether (MTBE)," Chemosphere, vol. 49, no. 4, pp. 413-420, 2002.

[30] Q. Zhang, J. Chen, C. Dai, Y. Zhang, and X. Zhou, "Degradation of carbamazepine and toxicity evaluation using the $\mathrm{UV} /$ persulfate process in aqueous solution," Journal of Chemical Technology and Biotechnology, vol. 90, no. 4, pp. 701-708, 2015.

[31] E. Bazrafshan, S. Noorzaei, and F. K. Mostafapour, "Photocatalytic degradation of aniline in aqueous solutions using magnesium oxide nanoparticles," Journal of Mazandaran University of Medical Sciences, vol. 26, no. 139, pp. 126-136, 2016.

[32] C. Tan, N. Gao, Y. Deng, N. An, and J. Deng, "Heat-activated persulfate oxidation of diuron in water," Chemical Engineering Journal, vol. 203, pp. 294-300, 2012.

[33] J. Wu, H. Zhang, and J. Qiu, "Degradation of Acid Orange 7 in aqueous solution by a novel electro/ $\mathrm{Fe}^{2+} /$ peroxydisulfate process," Journal of Hazardous Materials, vol. 215-216, pp. 138145, 2012.

[34] T. Chaoqun, F. Dafang, G. Naiyun, Q. Qingdong, X. Yan, and X. Huiming, "Kinetic degradation of Chloramphenicol in Water by UV/Persulfate system," Journal of Photochemistry and Photobiology A: Chemistry, vol. 332, pp. 406-412, 2017.

[35] L. Hou, H. Zhang, and X. Xue, "Ultrasound enhanced heterogeneous activation of peroxydisulfate by magnetite catalyst for the degradation of tetracycline in water," Separation and Purification Technology, vol. 84, pp. 147-152, 2012. 

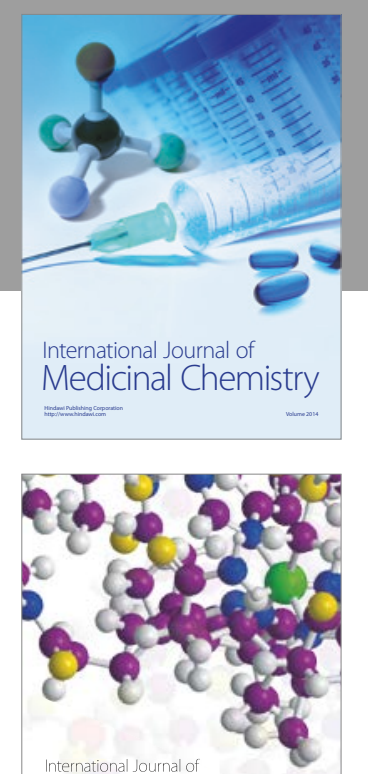

Carbohydrate Chemistry

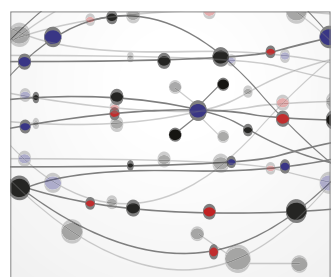

The Scientific World Journal
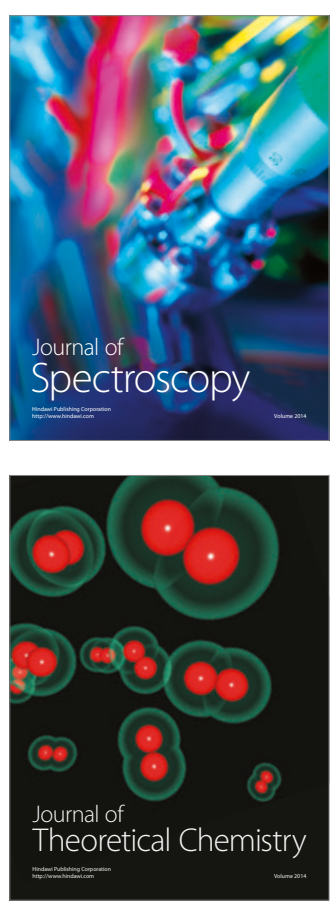
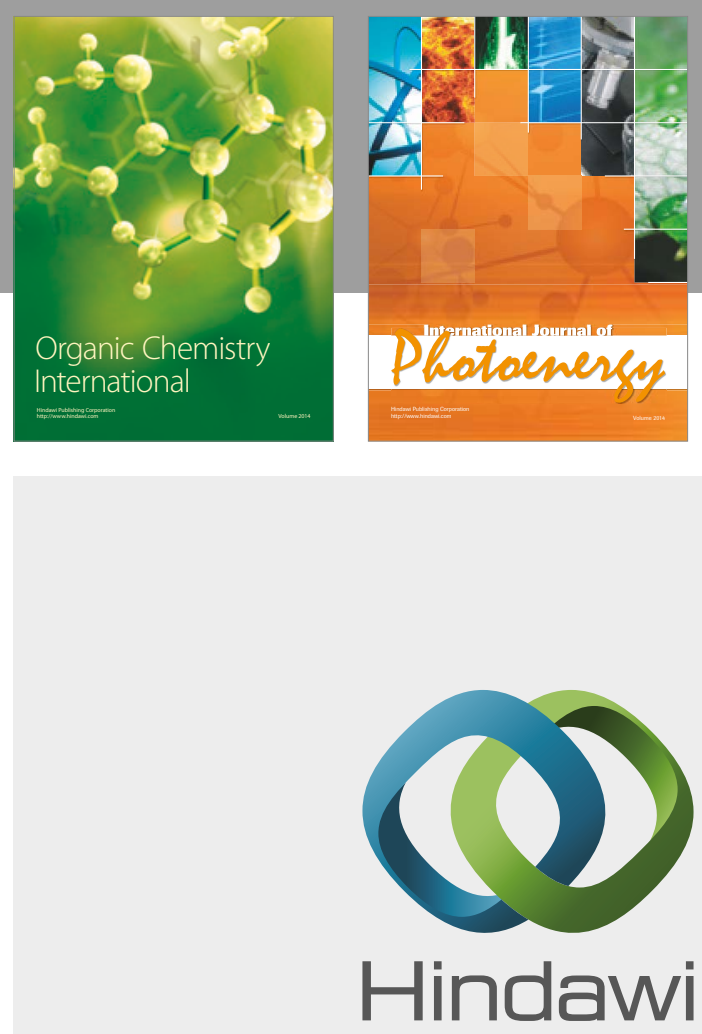

Submit your manuscripts at

https://www.hindawi.com

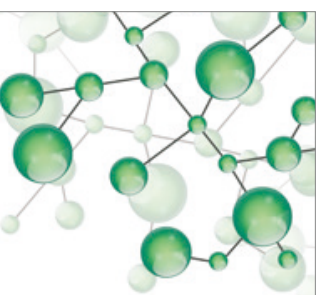

International Journal of

Inorganic Chemistry

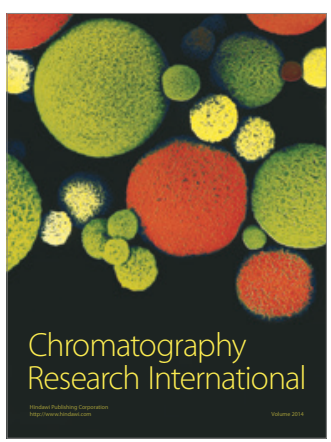

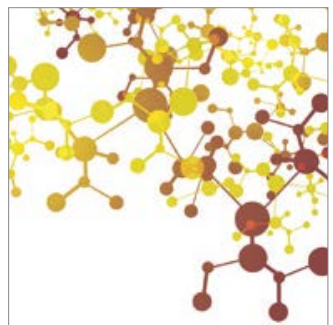

Applied Chemistry
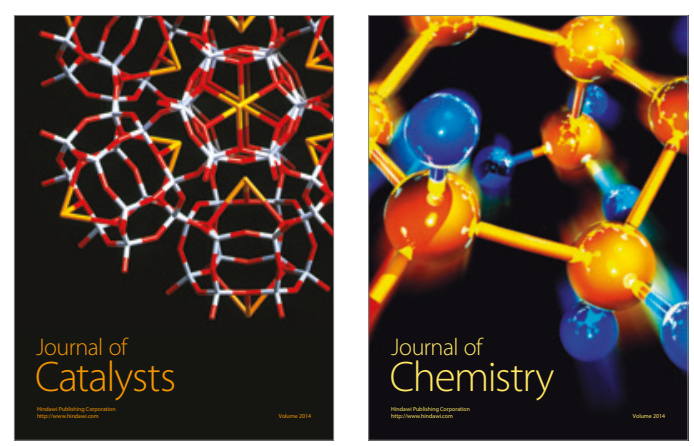
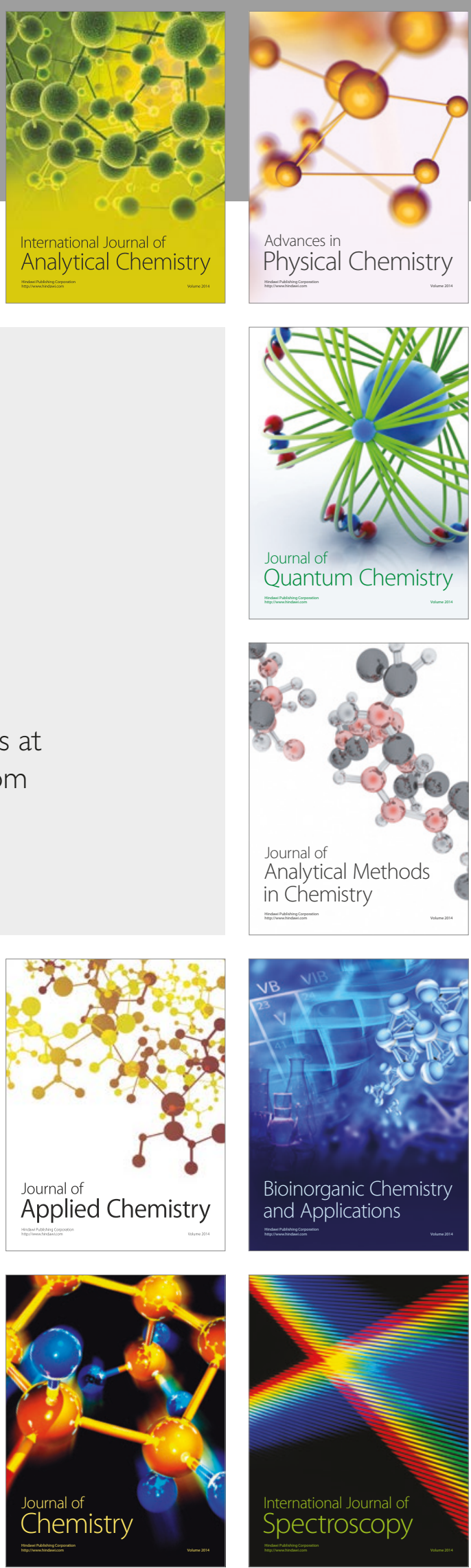